\title{
As lutas feministas na sociedade capitalista
}

Feminist Struggles in the Capitalist Society

\author{
Naylane Araújo Matos ${ }^{1}$ (iD 0000-0003-2077-1534 \\ Renata Porcher Scherer ${ }^{2}$ (iD) 0000-0003-2331-1453
}

'Universidade Federal de Santa Catarina, Programa de Pós-Graduação em Estudos da Tradução, Florianópolis, SC, Brasil. 88040-900-ppget@contato.ufsc.br

${ }^{2}$ Instituto Federal de Educação, Ciência e Tecnologia Sul-rio-grandense, Campus Camaquã, Camaquã, RS, Brasil.96180000-camaqua@ifsul.edu.br

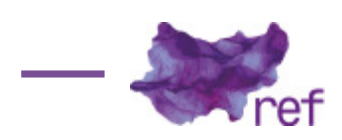

ARRUZZA, Cinzia; BHATTACHARYA, Tithi; FRASER, Nancy.

Feminismo para os 99\%: um manifesto.

Trad. de Heci Regina Candiani. São Paulo: Boitempo, 2019.

A obra Feminism for the 99 percent: a manifesto, das autoras Cinzia Arruzza, Tithi Bhattacharya e Nancy Fraser, teve lançamento simultâneo em diferentes países, incluindo o Brasil, na ocasião do $8 \mathrm{M}-8$ de março de 2019. As autoras, além do trabalho de docência e pesquisa sobre a relação entre o capitalismo e a opressão social de gênero, atuando em universidades dos Estados Unidos, são organizadoras e apoiadoras da Greve Internacional de Mulheres, de onde emerge o projeto deste manifesto, publicado no Brasil pela editora Boitempo, com tradução de Heci Regina Candiani, Feminismo para os 99\%: um manifesto.

O manifesto encontra-se dividido em 11 teses, nas quais buscam sustentar a defesa de um feminismo verdadeiramente emancipatório para 99\%, como uma resposta política e ética ao contexto atual de avanço das políticas neoliberais e neoconservadoras em todo o mundo; um feminismo que questione a concepção universalista da categoria mulher, que atenda às demandas das mulheres negras, das mulheres indígenas, das mulheres pobres, das mulheres marginalizadas, da classe trabalhadora; um feminismo anticapitalista, antirracista, ecossocialista, antiLGBTfóbico e internacionalista.

Na introdução, denominada "Encruzilhada", as autoras apresentam o feminismo liberal como um inimigo a ser combatido, visto que tem se constituído como uma espécie de "serviçal do capitalismo" (Cinzia ARRUZZA; Tithi BHATTACHARYA; Nancy FRASER, 2019, p. 26). Este modelo de feminismo, prioritariamente composto por mulheres executivas, se basearia no princípio lean in (faça acontecer), defendendo que mulheres ocupem lugares de destaque em grandes empresas e sustentando os discursos de empoderamento da mulher. O manifesto, no entanto, apresenta uma crítica contundente a tal modelo, visto que, diante da atual forma neoliberal do capitalismo, sua promessa emancipatória é um total equívoco e beneficia uma parcela ínfima de mulheres ainda assim em desvantagens se comparado aos homens de sua classe. À grande maioria das mulheres, às $99 \%$, resta o trabalho mal remunerado e precarizado, especialmente às mulheres negras, e maior vulnerabilidade ao abuso e ao assédio nos ambientes de trabalho. Além disso, os salários, muitas vezes, são insuficientes para cobrir os custos de reprodução social e as mulheres são obrigadas a trabalhar em múltiplos empregos, com dificuldades quanto à moradia, à 
educação, à segurança e segurança alimentar, à saúde, ao lazer, negligenciados pelos Estados que veiculam os interesses do capital.

A luta contra as ações que visam beneficiar o capital financeiro às custas da retirada de direitos da classe trabalhadora, extinguindo qualquer possibilidade de emancipação social para as/os $99 \%$ de que falam o manifesto, tem sido encampada pelas mulheres, por entenderem de que forma elas se relacionam às opressões de gênero. Não é à toa que, no Brasil, vimos nas eleições de 2018 um dos maiores atos organizados pelo movimento de mulheres, contra a candidatura de Jair Bolsonaro e a campanha \#elenão. Igualmente, as autoras do manifesto iniciam com a tese "Uma nova onda feminista está reinventando a greve" (ARRUZZA; BHATTACHARYA; FRASER, 2019, p. 31). Elas partem da organização das ações nacionais que resultaram no movimento transnacional do 8 de março de 2017, o 8M. Para elas, "as grevistas restabeleceram as raízes históricas quase esquecidas dessa data: a classe trabalhadora e o feminismo socialista" (ARRUZZA; BHATTACHARYA; FRASER, 2019, p. 32).

Assim, de acordo com as duas primeiras teses do manifesto, estaria emergindo um novo modelo de feminismo, nomeado pelas autoras como feminismo combativo, o qual redescobre "a ideia do impossível, reivindicando tanto pão como rosas: o pão que durante décadas o neoliberalismo tirara de nossas mesas, mas também a beleza que nutre nosso espírito por meio da euforia da rebelião" (ARRUZZA; BHATTACHARYA; FRASER, 2019, p. 36).

A terceira e quarta teses pautam a relação entre o capitalismo e a opressão de gênero e, portanto, a necessidade de um feminismo que lute contra a sociedade capitalista. Como argumentam as autoras, "o capitalismo não é apenas um sistema econômico, e sim algo maior: uma ordem social institucionalizada que abrange relações aparentemente não econômicas e práticas que mantêm a economia oficial" (ARRUZZA; BHATTACHARYA; FRASER, 2019, p. 102).

Isso significa que por trás das instituições oficiais do capitalismo, que gerem o sistema econômico, há outros constituintes que suportam e possibilitam tal economia, dentre os quais está a exploração do trabalho não assalariado e expropriado, executado predominantemente por mulheres, por exemplo. Nesse sentido, as autoras explicam que as contradições e crises do capitalismo referidas no manifesto não podem ser entendidas apenas em termos econômicos, com os colapsos do mercado financeiro ou desempregos em massa, mas estas se dão também em outras ordens: ecológica, política e de reprodução social.

Na ordem ecológica, abordada na nona tese, temos visto como o capitalismo se apropria da natureza gratuita e desenfreadamente para acumulação ampliada do capital, como aponta Virgínia Fontes (2006), e de que forma isso afeta a vida da classe trabalhadora. Exemplos brasileiros contundentes são os rompimentos de barragem em Mariana (2015) e Brumadinho (2019), em Minas Gerais. Quanto à ordem política, é necessário entender a sua correlação com a impulsão financeiro-imperialista. O capitalismo gera, nutre e reproduz Estados, com seu papel coercitivo e repressivo, a fim de controlar a força de trabalho e impulsionar, de forma ampliada, a exploração de recursos e o acúmulo de lucros (FONTES, 2006).

Ademais, a impulsão financeiro-imperialista interfere no processo político mediante o financiamento de partidos que veiculam os interesses do capital. No Brasil, vemos claramente um exemplo da intervenção imperial no processo político, quando os Estados Unidos financiaram organizações da sociedade civil, como o Movimento Brasil Livre (MBL) que promoveu o impeachment da Presidenta Dilma Rousseff (2016), conforme salienta Boaventura de Sousa Santos (2018). O golpe teve apoio do imperialismo norte-americano para levar adiante os interesses da burguesia brasileira que se alinha com os interesses do capital: enfraquecer quaisquer forças e organizações que buscam subverter as bases sociais desiguais (SANTOS, 2018). Nesse sentido, medidas como as reformas trabalhista e da previdência atingem diretamente as mulheres e outros grupos historicamente marginalizados e explorados pelo capital, acentuando o esgotamento da reprodução social.

A reprodução social, conforme definem as autoras do manifesto, diz respeito à

necessidade de os seres humanos se sustentarem por meio de processos que chamamos de produção de pessoas. [...] Abrange atividades que sustentam seres humanos como seres sociais corporificados que precisam não apenas comer e dormir, mas também criar suas crianças, cuidar de suas famílias e manter suas comunidades, tudo isso enquanto perseguem esperanças para o futuro. (ARRUZZA; BHATTACHARYA; FRASER, 2019, p. 106).

É na ordem da reprodução social, na qual o capitalismo se beneficia o máximo possível do trabalho reprodutivo "livre" para maximizar lucros, que melhor se compreende a assimetria de gênero. Isso porque essas atividades de produção de pessoas, como sabemos, são recaídas sobre as mulheres. Assim, para além das atividades que uma trabalhadora exerce no seu trabalho assalariado, ela também realiza o trabalho de reprodução de pessoas para ela e sua família, ficando sobrecarregada com uma dupla ou trilha jornada de trabalho. Essa é a faceta que o capitalismo quer ocultar: "o trabalho assalariado para obtenção de lucro não poderia existir sem o trabalho (na maioria das vezes) não assalariado da produção de pessoas" (ARRUZZA; BHATTACHARYA; FRASER, 2019, p. 108). 
Embora o trabalho de produção de pessoas não seja inerente à sociedade capitalista, tendo sempre existido, é nela que se dá a distinção entre trabalho econômico e reprodução social, no qual o primeiro tornou-se remunerado com salário e o segundo foi feminizado e sentimentalizado, ligado ao cuidado por amor - em oposição ao trabalho realizado por dinheiro, e, portanto, delegado às mulheres. Disso, emerge uma contradição, pois a acumulação do capital depende da participação efetiva de toda classe trabalhadora na sociedade, incluindo o trabalho remunerado também realizado por mulheres. Daí decorre que, além de as mulheres serem responsabilizadas pela produção de pessoas - cujo valor não é reconhecido pelo capitalismo , para garantir seu sustento e da sua família, elas precisam vender sua força de trabalho.

Diante disso, a autoras veem na atual crise do capitalismo uma possibilidade de transformação social através de um despertar político, argumentando que seriam nos momentos de crise que "as massas críticas da população retiram seu apoio a quem detém o poder" (ARRUZZA; BHATTACHARYA; FRASER, 2019, p. 47) e, nesse contexto, buscariam novas ideias, organizações e alianças.

A quinta tese sustenta que a opressão de gênero encontra-se enraizada na subordinação da reprodução social à produção que visa ao lucro. Nesse sentido, as lutas em torno da reprodução social, conforme defendem, precisam ocupar o centro dos debates e possuem potencial para alterar a sociedade por completo. A sexta tese discorre acerca do tema da violência de gênero e analisa duas formas de violência: privada e pública. As autoras destacam que essas duas formas de violência não estão separadas, mas que "algumas formas de violência de gênero pública e privada formam um círculo vicioso em que se reforçam mutuamente" (ARRUZZA; BHATTACHARYA; FRASER, 2019, p. 60).

A sétima tese, "O capitalismo tenta regular a sexualidade. Nós queremos libertá-la", detémse sobre as diferentes formas de como o capitalismo tem buscado regular a sexualidade da população. Se de um lado podemos observar o crescimento de medidas neoconservadoras que buscam criminalizar determinadas práticas sexuais por violar leis divinas ou valores familiares, também observamos o crescimento de forças liberais que apresentam em suas pautas os direitos legais das dissidências e das minorias sexuais. No entanto, as autoras nos alertam que tanto as políticas neoconservadoras como o liberalismo sexual não atuariam de forma divergente. Para elas, "o reacionarismo sexual encontra sua imagem espelhada no liberalismo sexual" (ARRUZZA; BHATTACHARYA; FRASER, 2019, p. 71). Nesse contexto, seria necessário libertar a sexualidade tanto das normatividades que operam a partir da noção de família nuclear como também atentar para as restrições de gênero, classe e raça junto com as "deformações do estatismo e do consumismo" (ARRUZZA; BHATTACHARYA; FRASER, 2019, p. 73).

A oitava e a nona teses defendem um feminismo antirracista, anti-imperialista e ecossocialista. Com relação ao racismo, importa registrar que desde sua origem, o feminismo apresenta um entrelaçamento histórico com atitudes racistas e torna-se urgente romper com tais posicionamentos, pois, conforme argumentam, "nada que mereça o nome 'liberação das mulheres' pode ser alcançado em uma sociedade racista, imperialista" (ARRUZZA; BHATTACHARYA; FRASER, 2019, p. 77). O tema do ecossocialismo é apresentado como uma pauta que já tem sido assumida por várias organizações de mulheres que têm produzido "formas novas e integradas de luta, que desafiam a tendência que ambientalistas convencionais têm de formular a defesa da 'natureza' e do bem-estar material das comunidades humanas como mutuamente opostos" (ARRUZZA; BHATTACHARYA; FRASER, 2019, p. 85).

A décima e a décima primeira teses defendem respectivamente o internacionalismo feminista e a união dos movimentos radicais pela insurgência anticapitalista comum, nas quais defendem que o feminismo para $99 \%$ precisa unir forças com outros movimentos anticapitalistas mundo afora. Dessa forma, se posicionam contrárias às ideologias da multiplicidade, afirmando que "as várias opressões que sofremos não formam uma pluralidade incipiente e contingente. Embora cada uma tenha as próprias formas e características, todas estão enraizadas em um único e mesmo sistema social e são por ele reforçadas" (ARRUZZA; BHATTACHARYA; FRASER, 2019, p. 95). Será ao identificar esse sistema como capitalismo que poderemos unir forças e combatê-lo, superando as divisões que o capital cultiva entre nós: culturais, raciais, étnicas, sexuais e de gênero. 0 horizonte histórico defendido pelas autoras como alternativa para o fim do capitalismo e suas opressões é, portanto, o socialismo.

Sabemos que muitas críticas têm sido destinadas às feministas socialistas, sob o argumento de sobreporem as questões de classe às questões de gênero. No entanto, como coloca Angela Davis (2016) em Mulheres, raça e classe - publicado também pela Boitempo e traduzido pela mesma tradutora do Manifesto -, nenhuma categoria deve ser entendida isoladamente nem as análises devem hierarquizar os modos de opressão, mas lutar contra opressão de gênero e racial sem ter em vista o fim do capitalismo é uma ação ineficaz. Isso não quer dizer que questões subjetivas não devam ser pautadas, inclusive, muitas das teses defendidas no manifesto se detêm sobre outras especificidades, como vimos, mas as autoras entendem que estas estão diretamente 
ligadas ao modo de produção e por isso defendem a luta contra o capitalismo para verdadeira emancipação das mulheres.

\section{Referências}

ARRUZZA, Cinzia; BHATTACHARYA, Tithi; FRASER, Nancy. Feminismo para os 99\%: um manifesto. Trad. de Heci Regina Candiani. São Paulo: Boitempo, 2019.

DAVIS, Angela. Mulheres, raça e classe. Trad. de Heci Regina Candiani. São Paulo: Boitempo, 2016.

FONTES, Virginia. "Imperialismo, classes sociais e conjuntura: capitalismo autônomo?". O cumuneiro [online], n. 3, 2006. Disponível em http://www.ocomuneiro.com/nr03_03_virginia.htm. Acesso em: $12 / 05 / 2019$.

SANTOS, Boaventura de Sousa. Esquerdas do mundo, uni-vos. São Paulo: Boitempo, 2018.

Naylane Araújo Matos (naylaneam@gmail.com) é tradutora e doutoranda no Programa de Pós-Graduação em Estudos da Tradução da Universidade Federal de Santa Catarina (UFSC), com bolsa CNPq. Membro do Grupo de Estudos Feministas na Literatura e na Tradução (GEFLIT/ UFSC). Mestra em Estudos da Tradução pelo Programa de Pós-Graduação em Estudos da Tradução (PGET/UFSC). Graduada em Letras - inglês pela Universidade do Estado da Bahia (UNEB).

Renata Porcher Scherer (renatapscherer@gmail.com) é doutora e mestra em Educação, especialista em Educação Especial e graduada em Educação Física pela Universidade do Vale do Rio dos Sinos (Unisinos). Licenciada em Pedagogia pela Universidade Federal do Rio Grande do Sul. Atua como professora no Instituto Federal de Educação, Ciência e Tecnologia Sul-riograndense - Campus Camaquã. Integra o Grupo Interinstitucional de Pesquisa em Docências, Pedagogias e Diferenças (GIPEDI/CNPq).

\section{COMO CITAR ESSE ARTIGO DE ACORDO COM AS NORMAS DA REVISTA}

MATOS, Naylane Araújo; SCHERER, Renata Porcher. "As lutas feministas na sociedade capitalista". Revista Estudos Feministas, Florianópolis, v. 28, n. 1, e65798, 2020.

\section{CONTRIBUIÇÃO DE AUTORIA}

Elaboração e contribuição coletiva.

\section{FINANCIAMENTO}

Não se aplica.

CONSENTIMENTO DE USO DE IMAGEM

Não se aplica.

APROVAÇÃO DE COMITÊ DE ÉTICA EM PESQUISA

Não se aplica.

\section{CONFLITO DE INTERESSES}

Não se aplica.

\section{LICENÇA DE USO}

Este artigo está licenciado sob a Licença Creative Commons CC-BY International. Com essa licença você pode compartilhar, adaptar, criar para qualquer fim, desde que atribua a autoria da obra.

\section{HISTÓRICO}

